\title{
Criatividade escolar: relação entre tempo de experiência docente e tipo de escola
}

\author{
Criatividade, experiência docente e escola \\ Júlia Soares Rosa de Castro \\ Denise de Souza Fleith
}

\begin{abstract}
Resumo
Este estudo investigou a criatividade e barreiras pessoais à sua expressão entre professores com mais e menos experiência docente da $4^{\mathrm{a}}$ série do Ensino Fundamental de escolas públicas e particulares. Examinou-se ainda a percepção do clima de sala de aula para a criatividade entre alunos destes professores. Participaram desta pesquisa 52 professores e 967 alunos. Foram utilizados os Testes Torrance de Pensamento Criativo, o Inventário para Identificação de Barreiras à Criatividade Pessoal e a Escala Sobre Clima para a Criatividade em Sala de Aula. Os resultados indicaram diferenças significativas entre os professores com mais e menos tempo de docência em apenas uma medida de criatividade. Os professores de escolas particulares apresentaram um desempenho superior aos das escolas públicas quanto à criatividade. Quanto às barreiras à criatividade pessoal, não foi identificada diferença significativa entre os professores nos diversos fatores examinados. Os alunos dos professores mais experientes e os de escolas particulares avaliaram mais positivamente o clima de sala de aula para a criatividade.

Palavras-chave: criatividade; professores; escola.
\end{abstract}

\section{School creativity: relationship between teaching experience and type of school}

\begin{abstract}
This study investigated creativity and personal barriers for its expression amongst 4th elementary grade public and private school teachers of various degrees of teaching experience. The perception of the classroom climate for creativity amongst the students of these teachers was also examined. Fifty two teachers and 967 students participated in this research. The Torrance Tests of Creative Thinking, the Inventory to Identify Barriers to Personal Creativity, and the Classroom Climate Scale for Creativity were used. The results indicated significant differences between the teachers with less and greater teaching experience in one creativity measure only. Private school teachers had a higher performance on creativity when compared to public school teachers. With regards to the barriers on personal creativity, no significant difference between the groups of teachers was identified. The students of the most experienced teachers and the ones from private schools evaluated the creativity classroom environment more positively.
\end{abstract}

Keywords: creativity; teachers; school.

\section{Creatividad escolar: relación entre tiempo de experiencia docente y tipo de escuela}

\section{Resumen}

Este estudio investigó la creatividad y las barreras personales para su expresión entre profesores con más y menos experiencia docente del $4^{\circ}$ grado de la Enseñanza Primaria de escuelas públicas y privadas. Todavía se verificó la percepción del ambiente de la clase escolar para la creatividad entre alumnos de esos profesores. Participaron de esta investigación 52 profesores y 967 alumnos. Fueron utilizados los Testes Torrance de Pensamento Criativo, el Inventário para Identificação de Barreiras à Criatividade Pessoal y la Escala Sobre Clima para a Criatividade em Sala de Aula. Los resultados indicaron diferencias significativas entre los profesores con más y menos tiempo de docencia en apenas una medida de creatividad. Los profesores de escuelas privadas presentaron un rendimiento superior en creatividad en relación a los profesores de las escuelas públicas. En relación a las barreras a la creatividad personal, no fue identificada diferencia significativa entre los profesores en los diversos factores examinados. Los alumnos de los profesores con más experiencia y los de escuelas privadas evaluaron más positivamente el ambiente en clase para la creatividad.

Palabras clave: creatividad; profesores; escuela. 
Tendências recentes no estudo da criatividade destacam que este construto só pode ser percebido na interação de aspectos sociais, culturais e individuais. Segundo Csikszentmihalyi (1999), a criatividade não é encontrada dentro dos indivíduos, mas na articulação de aspectos referentes ao campo social, à área de conhecimento e ao background do indivíduo que organiza as informações. Neste sentido, averiguar "o que é a criatividade" especificamente se torna obsoleto, sendo mais interessante investigar outros aspectos como "onde está a criatividade", ou "como melhor desenvolvêla", ou ainda "que elementos constituem barreiras à sua expressão".

Como lembram Alencar e Fleith (2003), a expressão criativa não depende apenas das características individuais. $\mathrm{O}$ ambiente e o contexto sócio-histórico-cultural têm um papel fundamental na estimulação ou inibição do potencial criador de qualquer pessoa, pois somos seres sociais, influenciamos a cultura e o momento histórico e somos influenciados por eles.

Assim, em suas investigações, diversos autores passaram a dar mais importância às condições que favorecem o desenvolvimento da criatividade no ambiente educacional (Amabile, 1989; Fleith, 2000; Renzulli, 2001; Sternberg, 2006), considerando todos os seus elementos constitutivos, desde o ambiente físico até os recursos humanos. Além de atentar para condições propícias ao desenvolvimento de habilidades cognitivas e traços de personalidade ligados à criatividade, atenção também passa a ser dada às características de um clima de sala de aula favorável ao desenvolvimento do potencial criador em todos os seus aspectos
(Fleith \& Alencar, 2005). O professor aparece, então, como peça fundamental neste cenário.

Nos Referenciais para Formação de Professores (Brasil, 1999), elaborado pela Secretaria de Educação Fundamental, do Ministério da Educação, e nos Parâmetros Curriculares Nacionais (Brasil, 1997), são apresentadas algumas funções e obrigações do professor inclusive em termos legais. De acordo com o primeiro documento, "os professores são profissionais cuja ação influi de modo significativo na constituição da subjetividade de seus alunos como pessoas e como cidadãos" (p. 55). O segundo documento descreve, ainda, que não é suficiente focar a formação dos alunos para futuras atividades em termos das especializações tradicionais, mas, antes, o professor deve estar atento a proporcionar ao seu aluno oportunidades de desenvolver sua capacidade para aquisição e o desenvolvimento de novas competências, “em função de novos saberes que se produzem e demandam um novo tipo de profissional, preparado para poder lidar com novas tecnologias e linguagens" (p. 28). Em ambos documentos não são encontradas referências específicas ao papel do professor no desenvolvimento da criatividade de seus alunos, mas são consideradas atribuições relacionadas a isto. Ao professor, é delegada a função fundamental de contribuir para o desenvolvimento integral de seus alunos, no contexto escolar, e capacitá-los para as "novas relações entre conhecimento e o trabalho que exigem capacidade de iniciativa e inovação" (Brasil, 1997, p. 28), elementos diretamente associados à criatividade. Por isso, especial atenção deve ser dada ao preparo destes profissionais. 
No entanto, conforme afirma Donatoni (2002), o preparo que os professores encontram nos cursos de formação, de maneira geral, não passa de teorias acerca do processo educativo idealizado, sobre padrões comportamental e humano dos indivíduos, esquecendo-se de que cada professor trabalhará com uma realidade diferente e que cada padrão de comportamento tem suas variações de acordo com cada situação e indivíduo. Em síntese, não prima por uma educação que atinja efetivamente a criança e seu contexto. Falhas são também identificadas no que diz respeito especificamente às práticas docentes que estimulam a criatividade em sala de aula. Segundo Martínez (2002), este assunto é minimamente tratado nos cursos de formação de professores e não encontra um valor real na maioria das instituições de ensino.

Observa-se uma prática docente orientada mais pelas teorias do cotidiano do que pelas teorias científicas. Os próprios professores reclamam da distância entre o que aprendem em seus cursos de formação e o que realizam na prática. Além da desvinculação entre teoria e prática, outros problemas quanto à formação dos professores podem ser observados (Feldens, 1998): ênfase excessiva na modernização do ensino sem considerar o "porquê" e "para quem"; elevada ênfase nas dimensões técnicas desvinculadas das demais dimensões inerentes ao ensino e à escolarização; falta de articulação entre os fundamentos nas disciplinas básicas do curso.

Esse mesmo autor chama a atenção para o fato de que estudos a respeito da formação de professores evidenciam a existência de uma relação positiva entre as dificuldades enfrentadas na educação brasileira e o fracasso das instituições formadoras em educar e preparar professores para as "realidades" e "culturas" com as quais deverão lidar. Essa falta de preparo em lidar com as reais características do contexto apresentado pelas instituições formadoras pode gerar, em cadeia, profissionais inadequados teórica e tecnicamente para um "mundo de trabalho", uma vez que não dominam as habilidades e compreensões exigidas pelo mercado. Se os profissionais docentes concluem seus cursos de formação despreparados, torna-se interessante verificar o impacto da prática diária, dos anos de experiência em sala de aula, especialmente em termos de sua criatividade.

Como ressalta Martínez (2002), para otimizar o processo de desenvolvimento da criatividade no contexto escolar, é necessário considerar a criatividade dos alunos, da escola como organização e dos professores. Yelós (2002) defende ser necessário que os membros da escola, em especial os professores e suas práticas sejam criativos, para que o processo educativo seja efetivo em termos de desenvolvimento do potencial criador. Utilizar a criatividade como ferramenta para gerar estratégias para um processo de ensinoaprendizagem efetivo dentro de sala de aula tornase então uma necessidade de cada docente (Martínez, 2002).

Em um estudo realizado por Hong, Hong, ChanLin, Chang e Chu (2005) que contou com a participação de professores premiados por suas práticas de ensino criativas, também foram evidenciadas algumas estratégias utilizadas por estes profissionais como: realização de atividades centradas no aluno; conexão entre os conteúdos ensinados e a vida real; administração de habilidades em sala; utilização de questões com 
mais de uma resposta; encorajamento do pensamento criativo; e uso de recursos tecnológicos e multimídias.

Para compreender os aspectos envolvidos com o trabalho docente e a criatividade, Mariani e Alencar (2005) conduziram uma pesquisa com professores de história do ensino fundamental. Os fatores mais enfatizados como facilitadores da criatividade foram a liberdade e a paixão pelo trabalho. Por outro lado, as barreiras identificadas estavam relacionadas a problemas no relacionamento professor/aluno, como a falta de habilidade de lidar com o discente.

Oliveira (2003) também encontrou resultados interessantes em um estudo com o objetivo de investigar a percepção de professores sobre procedimentos úteis para a promoção da criatividade em sala de aula. Os professores reconhecem a importância de desenvolver a criatividade em sala de aula, manifestam desejo de ministrar aulas mais criativas, mas apontam muitas barreiras que dificultam esta prática, como a falta de tempo para preparar e ministrar as aulas, excesso de conteúdo a ser ministrado e ausência de apoio da direção da escola.

Podemos concluir que apesar de muito importante e útil no sentido de orientar o professor em sua prática diária em sala de aula, definir atitudes e estratégias para proporcionar um clima favorável à criatividade não é suficiente. É essencial investir na criatividade do próprio docente e na identificação das possíveis barreiras à sua expressão. Alencar e Martínez (1998) explicam que o "desenvolvimento da criatividade na educação passa necessariamente pelo nível de criatividade dos profissionais que nela atuam. Conhecer as barreiras que enfrentam constitui uma condição necessária” (p. 31) para pensar em estratégias que possibilitem sua superação.

Diante deste panorama, o presente estudo teve como objetivo examinar a criatividade de professores da $4^{\mathrm{a}}$ série do ensino fundamental, de escolas públicas e particulares, com menos experiência docente e de professores com mais experiência em sala de aula, além das barreiras pessoais apontadas por estes dois grupos. Foi investigada também a percepção dos alunos desses professores acerca do clima de sala de aula. A criatividade dos professores, com menos experiência em sala de aula ou os com mais tempo de docência, pode interferir na forma como eles agem em relação aos seus alunos e executam suas atividades docentes. Enfim, este fenômeno pode estar relacionado à qualidade com que docentes ministram suas aulas e as tornam mais interessantes aos alunos, facilitando o processo de ensinoaprendizagem, e contribuindo para o seu desenvolvimento integral.

Alencar (2001) salienta que o professor pode tanto facilitar como inibir o desenvolvimento da expressão da criatividade e o crescimento do aluno. Para Fleith (2000), no cotidiano de sala de aula a implementação de práticas favoráveis ao potencial criador ocorre de maneira intuitiva, apesar de os professores reconhecerem a importância de se estimular a criatividade no contexto escolar. Cropley (2006) conclui que, para o professor promover a expressão criativa, é necessário empregar metodologias diversificadas e proporcionar espaços favoráveis à criatividade, fazendo, assim, uso de recursos criativos próprios. Diante disto, a própria criatividade do docente se 
torna fator essencial dentro do contexto de sala de aula.

Espera-se que este estudo possa fornecer às instituições de ensino e aos professores, oferecer subsídios para implementação de estratégias que favoreçam o processo de aprendizagem e de práticas que estimulem o desenvolvimento da criatividade dos alunos, contribuindo ainda para uma melhor formação docente.

\section{Método}

\section{Delineamento}

No presente estudo foi utilizado um delineamento fatorial $2 \times 2$. As variáveis independentes foram: tempo de docência (professores mais experientes e menos experientes) e tipo de escola (pública e particular). As variáveis dependentes foram: criatividade, barreiras à sua expressão e percepção do clima de sala de aula para criatividade (Gall, Borg \& Gall, 1996).

\section{Participantes}

Colaboraram com este estudo dois grupos de participantes: professores da $4^{\mathrm{a}}$ série $^{3}$ do Ensino Fundamental e seus alunos. Quanto ao grupo de professores, a pesquisa contou com a participação de 53 docentes, sendo $23(43,4 \%)$ de escolas públicas e $30(56,6 \%)$ de escolas particulares. Com o intuito de garantir maior abrangência da amostra, foram escolhidos professores de escolas diferentes,

\footnotetext{
${ }^{3}$ Recentemente o MEC passou a adotar a terminologia $5^{\circ}$ ano para se referir a $4^{a}$ série do ensino fundamental. Mas optou-se por manter a terminologia antiga uma vez que a maioria das escolas que participou desta pesquisa ainda não havia adotado a nova terminologia no momento da coleta de dados.
}

de acordo com a disponibilidade para participação na pesquisa, dada a dificuldade de seleção randômica dos participantes, uma vez que a participação dos professores na pesquisa foi voluntária, as escolas foram selecionadas por conveniência no Distrito Federal.

Quanto ao gênero, todos os participantes eram mulheres, possivelmente porque a $4^{\mathrm{a}}$ série foi privilegiada, e as séries iniciais estão, geralmente, sob responsabilidade de profissionais do sexo feminino. A idade das professoras variou de 18 a 55 anos, tendo média igual a 33,9 anos. Destaca-se, contudo, a diferença de idade entre professoras de escolas públicas e particulares. A média de idade das professoras de escolas públicas foi de 38,3 anos sendo superior à das docentes da rede particular, de 30,5 anos. Quanto à formação, 26 (49,1\%) professoras concluíram curso de nível superior e 15 $(28,3 \%)$ ainda estavam cursando a graduação. Sete $(13,2 \%)$ realizaram curso de especialização e 4 (7,5\%) ainda não haviam concluído a pósgraduação lato sensu. Apenas uma (1,9\%) professora possuía mestrado.

Em relação ao tempo de docência, as participantes apresentaram uma média de 11,6 anos de profissão, variando entre 1 e 29 anos. A média das professoras de escola pública foi de 15,3 anos e de particular 8,8 anos. Para investigar as questões de pesquisa propostas neste estudo, as professoras foram divididas em dois grupos pelo tempo de docência: professoras com menos de 6 anos de profissão totalizando 24 docentes, sendo $6(25,0 \%)$ de escola pública e $18(75,0 \%)$ de escola particular, e professoras com mais de 10 anos de profissão totalizando 29 profissionais, sendo $17(58,6 \%)$ de escola pública e $12(41,4 \%)$ de escola particular. 
Foi utilizado este ponto de corte porque o próprio grupo de professoras apresentou tal característica no quesito tempo de docência. Duas professoras que apresentaram tempo de docência entre 6 e 10 anos, não aceitaram participar de todas as etapas da pesquisa, sendo, portanto, excluídas da amostra.

O segundo grupo de participantes foi composto por 967 alunos destas professoras, sendo 451 (46,6\%) de escolas públicas e $516(53,4 \%)$ de escolas particulares. Quanto ao gênero, $509(52,6 \%)$ eram do sexo masculino e $457(47,3 \%)$ do sexo feminino. Um $(0,1 \%)$ aluno não informou o gênero. A idade média dos alunos foi 10,6 anos, variando entre 8 e 13 anos. Do total de participantes deste grupo, 461 (47,7\%) eram alunos de professores com menos de 6 anos de docência, enquanto que 506 $(52,3 \%)$ eram alunos de professores com mais de 10 anos de docência. Vale ressaltar que alguns professores que participaram do estudo não concordaram com a aplicação do instrumento em seus alunos, alegando falta de tempo.

\section{Instrumentos}

Teste Torrance de Pensamento Criativo - TTCT. Quatro subtestes da Bateria Torrance de Pensamento Criativo, forma B (Torrance, 1974; Wechsler, 2004a, 2004b), foram utilizados, com o intuito de avaliar a criatividade dos professores. Foram eles: Linhas Paralelas e Completando Figuras, ambos de natureza figurativa, e Usos Inusuais e Aperfeiçoando o Produto, ambos de natureza verbal. No subteste "Linhas Paralelas", é apresentado ao indivíduo uma série de pares de linhas paralelas nos quais ele deve fazer o maior número possível de figuras ou desenhos que conseguir em 10 minutos. As linhas devem ser a parte principal do desenho e o indivíduo pode desenhar tanto dentro quanto fora do espaço entre as linhas. No subteste "Completando Figuras" o indivíduo deve acrescentar linhas a 10 figuras incompletas apresentadas, fazendo desenhos ou objetos em que ninguém mais pensaria, em um tempo de 10 minutos. No subteste "Usos Inusuais", é solicitado ao indivíduo gerar o maior número possível de usos novos para caixas de papelão que normalmente são jogadas fora, em 5 minutos. As caixas podem ser de todos os tamanhos e o indivíduo pode usar quantas caixas quiser. No subteste "Aperfeiçoando o Produto" é solicitado ao indivíduo que liste, em 10 minutos, maneiras diferentes e interessantes de melhorar um elefante de brinquedo de forma que as crianças pudessem se divertir mais com ele.

Os subtestes foram avaliados nas categorias fluência, flexibilidade e originalidade, que Torrance (1974) considera como algumas das categorias para avaliação do pensamento criativo. Fluência é o número total de respostas ou idéias relevantes, relevância sendo definida em termos dos requisitos da tarefa como apresentados nas instruções. Flexibilidade corresponde ao número total de categorias em que as respostas poderiam ser enquadradas. Originalidade se baseia na raridade estatística das idéias expressas, sendo esta a freqüência de ocorrências das respostas no total das mesmas. Escores de 0, 1 e 2 foram dados dependendo da originalidade das respostas. Respostas cuja frequiência foi de $5 \%$ ou mais, receberam escore 0 . Aquelas com freqüência entre 2 e $4 \%$ receberam escore 1 e com freqüência inferior a $2 \%$ receberam escore 2 . 
O escore de criatividade verbal para cada professor foi obtido por meio da soma dos escores de fluência, flexibilidade e originalidade obtidos nos dois subtestes de natureza verbal e o escore de criatividade figurativa pela somatória das mesmas categorias dos subtestes figurativos. Obteve-se ainda um escore de criatividade total, resultado da soma dos escores de criatividade verbal e figurativa.

O teste foi validado no Brasil por Wechsler (2004a, 2004b) com um grupo de indivíduos criativos, por terem sua produção reconhecida na vida real, por prêmios e distinções em diversas áreas, e indivíduos não criativos ou regulares. A análise pela correlação de Pearson indicou relação significativa entre atividades criativas e indicativos criativos do teste $(r=0,14$ a $r=0,33, p \leq 0,05$ a $p \leq 0,001)$.

\section{Inventário para Identificação de Barreiras à} Criatividade Pessoal. Este inventário foi desenvolvido por Alencar (1999) e utilizado neste estudo para verificar as barreiras à criatividade pessoal identificadas pelo grupo de professores. $\mathrm{O}$ instrumento é composto por 66 itens e suas respostas apresentadas em escala Likert de 5pontos: (1) discordo plenamente; (2) discordo pouco; (3) em dúvida; (4) concordo pouco; (5) concordo plenamente. Nenhuma identificação é solicitada ao respondente. O comando para o preenchimento é: "eu seria mais criativo(a) se...".

$\mathrm{O}$ instrumento enfoca quatro fatores que podem ser considerados barreiras à expressão da criatividade pessoal, determinados pela análise fatorial: Inibição/Timidez (Fator 1); Falta de Tempo/Oportunidade (Fator 2); Repressão Social (Fator 3) e Falta de Motivação (Fator 4). O estudo de validação foi feito com base em respostas de estudantes do ensino superior e os coeficientes de fidedignidade obtidos para os fatores variam de 0,85 a 0,91 . A seguir alguns itens que compõem cada um desses fatores para melhor ilustração:

Fator 1 (Inibição/Timidez):

- Fosse menos tímido(a) para expor minhas idéias;

- Não tivesse medo de expressar o que penso.

Fator 2 (Falta de Tempo/ Oportunidade):

- Tivesse mais oportunidade de pôr em prática as minhas idéias;

- Tivesse tempo para elaborar minhas idéias.

Fator 3 (Repressão Social):

- Não tivesse recebido uma educação rígida;

- Tivesse tido mais oportunidade para errar sem ser taxado(a) de burro ou idiota.

Fator 4 (Falta de Motivação):

- Tivesse mais entusiasmo;

- Concentrasse mais no que faço.

Escala sobre Clima para a Criatividade em Sala de Aula. Esta escala, desenvolvida por Fleith e Alencar (2005), visa auxiliar na identificação de fatores que contribuem para a expressão da criatividade em sala de aula, bem como aqueles que inibem a criatividade segundo a percepção de alunos de $3^{\mathrm{a}}$ e $4^{\mathrm{a}}$ séries do ensino fundamental e foi utilizada com o grupo de alunos deste estudo. Intitulada "Minha Sala de Aula", a escala é composta por 22 itens de frase afirmativa e suas respostas apresentadas em escala Likert de 5pontos: (1) nunca; (2) poucas vezes; (3) algumas 
vezes; (4) muitas vezes; (5) sempre. Todos os cinco pontos da escala são indicados por escrito e representados graficamente por faces, a fim de facilitar a compreensão dos alunos respondentes. Nenhuma identificação é solicitada. O comando para o preenchimento é: "em minha sala de aula...".

A validade de construto da escala foi verificada por meio da análise fatorial exploratória da sua estrutura interna. Cinco fatores são medidos por esta escala: Suporte da Professora à Expressão de Idéias (Fator 1); Autopercepção do Aluno com Relação à Criatividade (Fator 2); Interesse do Aluno pela Aprendizagem (Fator 3); Autonomia do Aluno (Fator 4) e Estímulo da Professora à Produção de Idéias do Aluno (Fator 5). O estudo de validação foi feito com base em respostas de alunos de $3^{\mathrm{a}}$ e $4^{\mathrm{a}}$ séries do Ensino Fundamental e os coeficientes de fidedignidade obtidos para os fatores variam de 0,58 a 0,73. Segue abaixo alguns itens que compõem cada um desses fatores para melhor ilustração:

Fator 1 (Suporte da Professora à Expressão de Idéias):

- A professora dá atenção a minhas idéias;

- A professora se importa com o que eu tenho a dizer.

Fator 2 (Autopercepção do Aluno com Relação à Criatividade):

- Eu me acho criativo;

- Eu uso minha imaginação.

Fator 3 (Interesse do Aluno pela Aprendizagem):

- Os trabalhos que faço são divertidos;

- Eu gosto da matéria ensinada.

Fator 4 (Autonomia do Aluno):
- Eu procuro fazer as tarefas de maneira diferente;

- Eu posso escolher o que quero fazer.

Fator 5 (Estímulo da Professora à Produção de Idéias do Aluno):

- A professora me pede para pensar em novas idéias;

- A professora me pede para tentar quando não sei a resposta para uma questão.

\section{Procedimentos}

Para a coleta de dados, inicialmente entrou-se em contato com a direção e/ou coordenação pedagógica de cada escola, pedindo autorização para aplicar o instrumento em seus professores e alunos. Concedida a permissão, apresentou-se o instrumento e o consentimento informado aos docentes, na sala de professores, no horário de intervalo e/ou coordenação. Em algumas situações, o contato inicial foi feito diretamente com o professor. Foram agendados dois encontros para aplicação dos instrumentos de acordo com a disponibilidade de cada um.

As aplicações dos testes aconteceram de maneira individual e em grupo na sala dos professores, sala de reuniões da escola e sala de aula, no horário do intervalo ou coordenação, de acordo com a disponibilidade. No primeiro encontro, foram aplicados os subtestes "Completando Figuras", "Usos Inusuais" e "Linhas Paralelas" do Teste Torrance de Pensamento Criativo (TTCT), com duração cronometrada de 25 minutos, sendo 10 minutos para o primeiro e terceiro testes e 5 minutos para o segundo. No segundo encontro, foi aplicado o subteste "Aperfeiçoando o Produto", 
com duração cronometrada de 10 minutos, e o Inventário para Identificação de Barreiras à Criatividade Pessoal, que teve duração aproximada de 10 a 15 minutos. Vale ressaltar que foram seguidas todas as recomendações para alcance das condições ideais de administração do TTCT, conforme sugere Wechsler (2004a, 2004b).

\section{A Escala sobre Clima para a Criatividade em} Sala de Aula foi aplicada em um terceiro momento nos alunos dos professores. As aplicações ocorreram de forma coletiva, no primeiro momento da aula, com todos os alunos sentados em seus lugares. As carteiras estavam enfileiradas. Foram utilizados cerca de 20 minutos: 5 para distribuição do instrumento, explicação do comando e esclarecimento de eventuais dúvidas; e 15 para aplicação da escala. Cada item da escala foi lido junto com os alunos, para garantir sua compreensão. Enquanto realizavam a atividade, outras dúvidas foram esclarecidas. Foi solicitado ao professor que se ausentasse da sala durante a aplicação do instrumento em seus alunos. Alguns professores aproveitaram este momento para responder ao Inventário para Identificação de Barreiras à Criatividade Pessoal. Para análise dos dados, recorreu-se à análise de variância univariada (ANOVA) por meio do programa SPSS (Statistic Package for Social Science).

\section{Resultados}

Quanto à variável tempo de experiência docente, os resultados indicaram diferenças significativas apenas em relação à flexibilidade no subteste
Linhas Paralelas $(F[1,51]=5,066 ; p=0,029)$ (veja Tabela 1). Os professores com mais experiência apresentaram desempenho superior $(M=11,69$; $D P=2,98)$ em comparação com os professores com menos tempo de docência $(M=9,83 ; D P=3,00)$.

Considerando o tipo de escola, foram encontradas diferenças significativas entre professores em relação à fluência no mesmo subteste mencionado no parágrafo anterior $(F[1,51]=8,262 ; \quad p=0,006)$. Os professores de escolas particulares apresentaram desempenho superior $(M=14,13 ; D P=5,12)$ em comparação com os professores de escolas públicas $(M=10,87$; $D P=2,07)$. Na categoria originalidade do subteste Linhas Paralelas também foi encontrada diferença significativa entre professores dos dois tipos de escola $(F[1,51]=9,768 ; p=0,003)$. Os docentes de escolas particulares apresentaram desempenho superior $(M=9,83 ; D P=3,14)$ em comparação aos de escolas públicas $(M=7,65 ; D P=1,30)$ (veja Tabela 2).

No subteste Usos Inusuais, surgiu diferença significativa na categoria fluência $(F[1,51]=$ $5,900 ; p=0,019)$ entre os professores. Os docentes de escolas particulares apresentaram resultados superiores $(M=13,97 ; D P=5,95)$ em relação aos de escola pública $(M=10,78 ; \quad D P=2,30)$. No subteste Aperfeiçoando o Produto, diferença significativa foi observada também na categoria fluência $(F \quad[1,51]=4,175 ; p=0,046)$. Os professores de escolas particulares, mais uma vez, apresentaram resultados superiores $(M=14,80$; $D P=5,68)$ em comparação com os de escolas públicas $(M=12,26 ; D P=2,00)$ (veja Tabela 2$)$. Quanto às categorias criatividade verbal, figurativa e geral, foram encontradas diferença significativa 
em criatividade figurativa $(F[1,51]=4,932$; $p=0,031)$ e geral $(F[1,51]=7,165 ; p=0,010)$ entre os dois grupos de professores (veja Tabela 2). Os docentes de escolas particulares apresentaram desempenho superior em criatividade figurativa $(M=59,60 ; \quad D P=12,85) \quad$ e criatividade geral $(M=125,07 ; \quad D P=23,34)$ em relação aos de escolas públicas $(M=53,35 ; \quad D P=4,64$; $M=111,30 ; \quad D P=8,94)$. Os resultados indicaram ainda haver interação significativa entre tipo de escola e tempo de experiência docente apenas em relação à categoria originalidade do subteste Completando Figuras $(F[1,49]=6,665 ; p=0,013)$. Os professores com menos tempo de

Tabela 1. Valores de média, desvio-padrão e índices de ANOVA das medidas de criatividade dos professores com mais e menos anos de experiência docente.

\begin{tabular}{|c|c|c|c|c|c|c|c|}
\hline \multirow[t]{2}{*}{ Criatividade } & & \multicolumn{2}{|c|}{$\begin{array}{c}\text { Menos de } 6 \text { Anos de } \\
\text { Docência }\end{array}$} & \multicolumn{2}{|c|}{$\begin{array}{c}\text { Mais de } 10 \text { Anos de } \\
\text { Docência }\end{array}$} & \multirow[b]{2}{*}{$F$} & \multirow[b]{2}{*}{$p$} \\
\hline & & $M$ & $D P$ & $\bar{M}$ & $D P$ & & \\
\hline \multirow[t]{3}{*}{ Linhas Paralelas } & Fluência & 11,63 & 3,62 & 13,62 & 4,78 & 2,830 & 0,099 \\
\hline & Flexibil. & 9,83 & 3,00 & 11,69 & 2,98 & 5,066 & $0,029 *$ \\
\hline & Original. & 8,92 & 2,81 & 8,86 & 2,70 & 0,005 & 0,943 \\
\hline Usos & Fluência & 11.38 & 3,79 & 13,59 & 5,60 & 2,709 & 0,106 \\
\hline \multirow[t]{2}{*}{ Inusuais } & Flexibil. & 9,71 & 2,20 & 9,45 & 1,80 & 0,224 & 0,638 \\
\hline & Original. & 7,00 & 2,87 & 8,10 & 2,51 & 2,224 & 0,142 \\
\hline Completando & Fluência & 9,63 & 1,13 & 9,97 & 0,19 & 2,539 & 0,117 \\
\hline \multirow[t]{2}{*}{ Figuras } & Flexibil. & 7,96 & 1,49 & 8,28 & 0,70 & 1,043 & 0,312 \\
\hline & Original. & 6,67 & 1,86 & 6,34 & 1,70 & 0,434 & 0,513 \\
\hline Aperfeiçoando & Fluência & 13,96 & 6,00 & 13,48 & 3,16 & 0,137 & 0,713 \\
\hline \multirow[t]{2}{*}{ Produto } & Flexibil. & 10,38 & 2,43 & 10,34 & 2,39 & 0,002 & 0,964 \\
\hline & Original. & 8,33 & 3,27 & 8,45 & 2,60 & 0,020 & 0,887 \\
\hline Criatividade & & 60,75 & 15,80 & 63,41 & 12,54 & 0,468 & 0,497 \\
\hline \multicolumn{8}{|l|}{ Verbal } \\
\hline Criatividade & & 54,62 & 10,61 & 58,76 & 10,28 & 2,063 & 0,157 \\
\hline \multicolumn{8}{|l|}{ Figurativa } \\
\hline Criatividade & & 115,37 & 20,97 & 122,17 & 18,22 & 1,592 & 0,212 \\
\hline Geral & & & & & & & \\
\hline
\end{tabular}


Tabela 2. Valores de média, desvio-padrão e índices de ANOVA das medidas de criatividade dos professores de escolas públicas e particulares.

\begin{tabular}{|c|c|c|c|c|c|c|c|}
\hline \multirow{2}{*}{ Criatividade } & & \multicolumn{2}{|c|}{ Escola Pública } & \multicolumn{2}{|c|}{ Escola Particular } & \multirow{2}{*}{$F$} & \multirow{2}{*}{$p$} \\
\hline & & & & & & & \\
\hline \multirow[t]{3}{*}{ Linhas Paralelas } & Fluência & 10,87 & 2,07 & 14,13 & 5,12 & 8,262 & $0,006^{*}$ \\
\hline & Flexibil. & 10,17 & 2,08 & 11,37 & 3,65 & 1,959 & 0,168 \\
\hline & Original. & 7,65 & 1,30 & 9,83 & 3,14 & 9,768 & $0,003 *$ \\
\hline Usos & Fluência & 10,78 & 2,30 & 13,97 & 5,95 & 5,900 & $0,019 *$ \\
\hline \multirow[t]{2}{*}{ Inusuais } & Flexibil. & 9,00 & 1,60 & 10,00 & 2,15 & 3,495 & 0,067 \\
\hline & Original. & 7,39 & 1,23 & 7,77 & 3,46 & 0,246 & 0,622 \\
\hline Completando & Fluência & 9,96 & 0,21 & 9,70 & 1,02 & 1,398 & 0,243 \\
\hline \multirow[t]{2}{*}{ Figuras } & Flexibil. & 8,13 & 0,87 & 8,20 & 1,31 & 0,000 & 0,993 \\
\hline & Original. & 6,57 & 1,44 & 6,43 & 1,99 & 0,072 & 0,790 \\
\hline Aperfeiçoando & Fluência & 12,26 & 2,00 & 14,80 & 5,68 & 4,175 & $0,046^{*}$ \\
\hline \multirow[t]{2}{*}{ Produto } & Flexibil. & 10,04 & 1,52 & 10,60 & 2,88 & 0,704 & 0,405 \\
\hline & Original. & 8,48 & 1,62 & 8,33 & 3,60 & 0,032 & 0,859 \\
\hline Criatividade & & 57,96 & 6,17 & 65,47 & 17,29 & 3,939 & 0,053 \\
\hline \multicolumn{8}{|l|}{ Verbal } \\
\hline Criatividade & & 53,35 & 4,64 & 59,60 & 12,85 & 4,932 & $0,031 *$ \\
\hline \multicolumn{8}{|l|}{ Figurativa } \\
\hline Criatividade & & 111,30 & 8,94 & 125,07 & 23,34 & 7,165 & $0,010^{*}$ \\
\hline Geral & & & & & & & \\
\hline
\end{tabular}

docência de escolas particulares apresentaram escores mais altos nesta medida $(M=7,00$; $D P=1,91)$ do que os com menos tempo de experiência de escolas públicas $(M=5,67$; $D P=1,37)$. Por outro lado, os professores com mais tempo de docência de escolas públicas exibiram melhor performance nesta medida de criatividade $(M=6,88 ; D P=1,36)$ em comparação com os de maior experiência em sala de aula de escolas particulares $(M=5,58 ; D P=1,88)$.
Com relação às barreiras à criatividade pessoal, os resultados indicaram que não há diferença significativa entre os grupos de professores com mais ou menos tempo de experiência docente em relação às barreiras pessoais à expressão da criatividade. No entanto, pode-se observar que o Fator 2 (Falta de Tempo/Oportunidade) foi a barreira que obteve maior média tanto entre professores com menos experiência docente $(M=3,63 ; D P=0,69)$ quanto entre os docentes com mais experiência $(M=3,35 ; D P=0,65)$. 
Também não foram encontradas diferenças significativas em relação às barreiras pessoais à expressão da criatividade quando considerado o tipo de escola dos professores. Porém, como observado anteriormente, o Fator 2 (Falta de Tempo/Oportunidade) apareceu como a barreira com maior média tanto entre os professores de escolas públicas $(M=3,55 ; D P=0,65)$, quanto entre os docentes de escolas particulares $(M=3,41$;
$D P=0,70)$. Não foram encontradas interações significativas entre tipo de escola e experiência docente em relação às barreiras pessoais à expressão da criatividade.

Quanto à percepção do clima para criatividade em sala de aula, os resultados indicaram diferenças significativas entre os grupos de alunos de professores com menos e mais experiência docente

Tabela 3. Valores de média, desvio-padrão e índices de ANOVA relativos à percepção do clima para criatividade em sala de aula entre alunos dos professores com mais e menos tempo de experiência docente.

\begin{tabular}{lcccccc}
\hline $\begin{array}{l}\text { Percepção do Clima para } \\
\text { Criatividade em Sala de }\end{array}$ & $\begin{array}{c}\text { Menos de 6 Anos de } \\
\text { Docência }\end{array}$ & $\begin{array}{c}\text { Mais de 10 Anos de } \\
\text { Docência }\end{array}$ & & \\
Aula (Fatores) & $M$ & $D P$ & $M$ & $D P$ & $F$ & $p$ \\
\cline { 2 - 6 } & & & & & \\
\hline
\end{tabular}


em relação ao Fator 1 (Suporte da Professora à Expressão de Idéias) $(F[1,941]=17,007 ; p=0,001)$ (veja Tabela 3). Os alunos dos professores com mais tempo de docência consideraram que recebem maior suporte da professora à expressão de idéias $(M=3,99 ; \quad D P=0,74)$ em comparação com os alunos dos professores com menos experiência $(M=3,79 ; D P=0,80)$.

Os resultados também indicaram diferenças significativas entre estes grupos de alunos em relação ao Fator 3 (Interesse do Aluno pela Aprendizagem $)(F[1,931]=15,804 ; p=0,001)$ (veja Tabela 3). Os alunos dos professores com mais tempo de docência avaliaram o clima de sala de aula como mais estimulador do interesse pela aprendizagem $(M=4,22 ; D P=0,57)$ do que os alunos dos professores com menos experiência $(M=4,06 ; D P=0,65)$.

Quando considerada a variável "tipo de escola”, diferença significativa foi encontrada no Fator 2 (Autopercepção do Aluno em Relação à Criatividade $)(F[1,940]=22,903 ; p=0,001)$. Os alunos das escolas particulares se autoperceberam como mais criativos em sala de aula $(M=4,06$; $D P=0,71)$ do que os das escolas públicas $(M=3,83 ; D P=0,78)$. Também foi encontrada diferença significativa para o Fator 4 (Autonomia do Aluno $(F[1,936]=9,861 ; p=0,002)$. Os alunos das escolas particulares avaliaram o clima de sala de aula como mais favorecedor de sua autonomia $(M=2,85 ; \quad D P=0,83)$ do que os de escolas públicas $(M=2,67 ; D P=0,91)$.

Os resultados revelaram ainda interação significativa entre estes grupos de alunos em relação ao Fator 3 (Interesse do Aluno pela Aprendizagem $) \quad(F[1,929]=8,672 ; p=0,003)$. Os alunos dos professores com mais tempo de docência das escolas particulares apresentaram uma avaliação mais positiva deste Fator $(M=4,30$; $D P=0,53)$ em comparação com os alunos dos professores de escolas públicas mais experientes $(M=4,17 ; D P=0,59)$. Ao contrário, os alunos de professores com menos experiência docente de escolas públicas exibiram uma percepção mais favorável do Fator de clima de sala de aula relacionado ao interesse do aluno pela aprendizagem $(M=4,14 ; D P=0,60)$ do que os alunos de professores de escolas particulares menos experientes $(M=4,02 ; D P=0,67)$.

\section{Discussão e Conclusões}

Em relação à criatividade dos docentes, os resultados apontaram não haver diferença significativa nas distintas medidas levando-se em consideração o tempo de experiência docente, exceto na categoria flexibilidade do subteste Linhas Paralelas. De maneira geral, os dois grupos não podem ser efetivamente considerados distintos em relação à criatividade, apenas por esta única diferença, uma vez que se trata de um fenômeno complexo, envolvendo múltiplos aspectos. Neste sentido, o tempo de experiência não representaria um fator tão influente na criatividade dos docentes. Esta idéia contrapõe tanto o pressuposto de Simonton (1994) de que toda carreira possui um começo um meio e um fim constituindo uma trajetória com um ponto de partida, uma curva de ascensão, um pico e uma curva de decréscimo, também em relação à produtividade criativa, quanto com os resultados encontrados em pesquisa 
realizada, por exemplo, por $\mathrm{Wu}$, Cheng, Ip e McBride-Chang (2005). Segundo estes autores, a experiência contribui para a performance criativa em atividades que exijam conhecimento especializado, o que não aconteceu neste estudo.

Quanto à única diferença encontrada entre estes dois grupos na categoria flexibilidade do subteste Linhas Paralelas, algumas considerações podem ser traçadas. Trata-se de uma avaliação de natureza figurativa, voltada à compreensão de aspectos relacionados ao processo criativo, baseada na ação de criar expressa em forma de desenhos (Wechsler, 2004b). Entende-se que a flexibilidade corresponde à "habilidade de olhar o problema sob diferentes ângulos e de mudar os tipos de propostas para solucionar um problema" (p. 3). Na presente investigação identificou-se que os professores com mais experiência apresentaram desempenhos superiores nesta categoria, ou seja, são capazes de apresentar mais soluções diferentes para uma determinada situação se comparados aos professores com menos experiência.

Este resultado pode refletir a realidade dos cursos de formação docente que, aparentemente, não preparam tão bem seus alunos para a realidade da prática em sala de aula (Azanha, 1998). O fato de os professores com menos experiência apresentarem menor flexibilidade em uma medida de criatividade ilustra de maneira superficial a situação complicada em que se encontram os recém-formados, uma vez que saem de seus cursos de formação despreparados para fazer uma conexão satisfatória entre o que aprendem na teoria e sua prática docente (Donatoni, 2002).

Os resultados relativos ao tipo de escola em que estes professores exerciam suas atividades profissionais foram um pouco distintos. Os docentes das escolas particulares apresentaram maior desempenho na categoria fluência em quase todos os subtestes e na categoria originalidade do subteste figurativo Linhas Paralelas. Entende-se fluência a "capacidade de gerar um grande número de idéias e soluções para um problema" (Wechsler, 2004a, p. 3) e por originalidade a "capacidade de produzir idéias raras e incomuns, quebrando padrões habituais de pensar e gerando respostas incomuns dentro de um determinado grupo de pessoas" (p. 4).

De certa forma, os professores das escolas particulares demonstram maior capacidade de enfrentar os entraves de sua profissão, apresentando mais capacidade de encontrar maior número de soluções e idéias para uma situação, e oportunizar um ambiente mais propício à expressão criativa dos alunos. Isto pode ser explicado pelas melhores condições de trabalho encontradas na rede particular de ensino (Lapo \& Bueno, 2003), uma vez que este ambiente influencia claramente na criatividade dos profissionais.

Levando-se em consideração que a criatividade dos professores pode influenciar positivamente na produção criativa de seus alunos, os resultados do presente estudo estão de acordo com os encontrados em pesquisa realizada por Fleith (2007) em que alunos das escolas particulares apresentam melhor desempenho criativo em comparação com os alunos de escolas públicas.

Também foram examinadas, no presente estudo, as barreiras pessoais à expressão da criatividade entre os professores. No entanto, não foram encontradas diferenças significativas entre os grupos de docentes, nem quando considerado o 
tempo de experiência docente ou o tipo de instituição. Vale ressaltar que a principal barreira apontada tanto pelos professores de escolas públicas quanto de particulares, com menos ou mais experiência docente, foi o fator Falta de Tempo/Oportunidade. Este resultado também foi obtido por Alencar e Martínez (1998), Oliveira (2003) e Ribeiro (2006).

Aparentemente, o conteúdo extenso a ser coberto pelo professor além da falta de apoio da direção limita o tempo disponível e a motivação para se trabalhar o teor das aulas de forma crítica e criativa. Alencar, Fleith e Martínez (2003) chamam atenção para o enorme desperdício do talento criativo devido à falta de oportunidade para desenvolver e expressar este potencial. Além disso, na formação de professores a ênfase tem sido no domínio de conteúdos específicos da área e pouca atenção tem sido dada à aquisição de estratégias de ensino e técnicas de estimulação da criatividade em sala de aula.

Para complementar a visão da criatividade escolar, também foi examinada a percepção do clima de sala de aula dos alunos destes professores, por meio da Escala sobre Clima para a Criatividade em Sala de Aula. Quando considerados os alunos dos professores mais e menos experientes, os resultados indicaram que os alunos dos docentes mais experientes consideram que recebem mais suporte da professora à expressão de idéias e demonstraram uma percepção mais positiva do clima de sala de aula para o interesse pela aprendizagem. Talvez os professores mais experientes, por possuírem uma maior familiaridade com a instituição em que trabalham e com os alunos de maneira geral, apresentem uma melhor empatia com estes e isto acaba por influenciar positivamente sua forma de administrar as aulas. Conseqüentemente, seus alunos apresentam uma percepção do clima de sala de aula mais favorável do que os alunos de professores menos experientes. Estes hipoteticamente se dedicam mais a sua própria adaptação à nova instituição, à familiarização com o novo contexto e com sua própria aprendizagem, deixando de lado a melhora do clima de sala de aula.

Estes resultados estão de acordo com as idéias de diversos autores (Fleith, 2000; Hasirci \& Demirkan, 2003; McCoy \& Evans, 2002) que defendem a importância do ambiente escolar, principalmente de sala de aula, para a expressão criativa e aprendizagem dos alunos. O professor faz parte deste ambiente e sua atuação, suas práticas favorecem ou não o desenvolvimento da criatividade dos alunos, assim como a aprendizagem.

Como demonstram os resultados, os alunos dos professores com mais experiência encontram mais suporte em seus professores do que os alunos dos docentes com menos experiência. Talvez os professores novos na profissão estejam mais preocupados com a transmissão do conteúdo ou com outros aspectos como disciplina que acabam dando pouca atenção às idéias dos alunos. De certa forma, o incentivo à expressão de idéias influencia o interesse pela aprendizagem, pois os mesmos alunos que encontram o suporte dos professores mais experientes, também percebem o clima de sala de aula como estimulador do processo de ensinoaprendizagem.

Este estudo ressalta a necessidade de maior atenção ao desenvolvimento da criatividade em sala 
de aula, tanto do Ensino Fundamental, quanto dos cursos de formação docente. As instituições de ensino devem atentar para condições que favoreçam o clima de sala de aula para criatividade de seus alunos, assim como o desenvolvimento da criatividade de seus professores. Muitas vezes estes profissionais não encontram espaço, tempo e/ou oportunidades de exercitar sua criatividade, o que acaba interferindo no desenvolvimento da criatividade do grupo discente.

Com base nos resultados obtidos no presente estudo, sugerimos para pesquisas futuras: estudos longitudinais para investigar o impacto dos anos de docência, de sala de aula, de experiência na criatividade dos professores, investigando um mesmo grupo de docentes em diferentes momentos de suas carreiras; estudos comparativos entre professores de diversas séries investigando as variáveis idade, criatividade e tempo de experiência docente; estudos envolvendo observação em salas de aula a fim de investigar mais profundamente em que extensão as práticas pedagógicas de professores mais e menos experientes favorecem a expressão criativa dos alunos; investigações junto a direção e a coordenação pedagógica dentro das instituições escolares com o intuito de verificar a extensão em que a criatividade é valorizada pelos gestores educacionais.

\section{Referências}

Alencar, E. M. L. S. (1999). Barreiras à criatividade pessoal: desenvolvimento de um instrumento de medida. Psicologia Escolar e Educacional, 3, 123-132.
Alencar, E. M. L. S. (2001). Criatividade e educação de superdotados. Petrópolis: Vozes.

Alencar, E. M. L. S., \& Fleith, D. S. (2003). Criatividade: múltiplas perspectivas. Brasília: Editora Universidade de Brasília.

Alencar, E. M. L. S., Fleith, D. S., \& Martínez, A. M. (2003). Obstacles to personal creativity between Brazilian and Mexican university students: A comparative study. Journal of Creative Behavior, 37, 179-192.

Alencar, E. M. L. S., \& Martínez, A. M. (1998). Barreiras à expressão da criatividade entre profissionais brasileiros, cubanos e portugueses. Psicologia Escolar $e$ Educacional, 2, 23-32.

Amabile, T. A. (1989). Growing up creative. Buffalo, NY: The Creative Education Foundation Press.

Azanha, J. M. P. (1998). Comentários sobre a formação de professores em São Paulo. Em R. V. Serbino (Org.), Formação de professores (pp. 49-58). São Paulo: UNESP.

Brasil. (1997). Parâmetros curriculares nacionais. Brasília: MEC/SEF.

Brasil. (1999). Referenciais para formação de professores. Brasília: MEC/SEF.

Cropley, A. J. (2006). Creativity: A social approach. Roeper Review, 28, 125-131.

Csikszentmihalyi, M. (1999). Implications of a systems perspective for the study of creativity. Em R. J. Sternberg (Org.), Handbook of creativity (pp. 313-335). New York: Cambridge University Press.

Donatoni, A. R. (2002). A formação do professor de $1^{\mathrm{a}}$ a $4^{\mathrm{a}}$ série. Em M. C. Utsumi (Org.), Entrelaçando saberes: 
contribuições para a formação de professores e as práticas escolares (pp. 93-110). Florianópolis: Insular.

Feldens, M. G. F. (1998). Desafios na educação de professores: analisando e buscando compreensões e parcerias institucionais. Em R. V. Serbino (Org.), Formação de Professores (pp. 125-137). São Paulo: UNESP.

Fleith, D. S. (2000). Teacher and student perceptions of creativity in the classroom environment. Roeper Review, $22,148-152$.

Fleith, D. S. (2007). Características personológicas $e$ fatores ambientais relacionadas ao desenvolvimento da criatividade no contexto educacional (relatório técnico). Brasília: CNPq.

Fleith, D. S., \& Alencar, E. M. L. S. (2005). Escala sobre o clima para criatividade em sala de aula. Psicologia: Teoria e Pesquisa, 21, 85-91.

Gall, M. D., Borg, W. R., \& Gall, J. P. (1996). Educational research. New York: Longman.

Hasirci, D., \& Demirkan, H. (2003). Creativity in learning environment: The case of two sixth grade artrooms. Journal of Creative Behavior, 37, 17-41.

Hong, J. S., Hong, J. C., ChanLin, L. J., Chang, S. H., \& Chu, H. C. (2005). Creative teachers and creative teaching strategies. International Journal of Consumer Studies, 29, 352-358.

Lapo, F. R., \& Bueno, B. O. (2003). Professores, desencanto com a profissão e abandono do magistério. Cadernos de Pesquisa, 118, 65-88.

Mariani, M. F. M., \& Alencar, E.M. L. S. (2005). Criatividade no trabalho docente segundo professores de história: limites e possibilidades. Psicologia Escolar $e$ Educacional, 1, 27-35.
Martínez, A. M. (2002). A criatividade na escola: três direções de trabalho. Linhas Críticas, 8, 189-206.

McCoy, J. M., \& Evans, G. W. (2002). The potential role of the physical environment in fostering creativity. Creativity Research Journal, 14, 409-426.

Oliveira, A. L. A. (2003). Percepção de professores do ensino fundamental sobre procedimentos úteis à promoção da criatividade em sala de aula. Dissertação de Mestrado, Universidade Católica de Brasília, Brasília.

Renzulli, J. S. (2001). Enriching curriculum for all students. Arlington Heights, IL: SkyLight Professional Development.

Ribeiro, R. A. (2006). Percepção de professores e estudantes de cursos de licenciatura quanto ao estímulo à criatividade. Dissertação de Mestrado, Universidade de Brasília, Brasília.

Simonton, D. K. (1994). Greatness. New York: The Guilford Press.

Sternberg, R. J. (2006). The nature of creativity. Creativity Research Journal, 18, 87-98.

Torrance, E. P. (1974). Torrance Tests of Creative Thinking. Norms-technical manual. Bensenville, IL: Scholastic Testing Service.

Wechsler, S. M. (2004a). Avaliação da criatividade por palavras - Teste de Torrance: versão brasileira. Campinas: LAMP-PUC.

Wechsler, S. M. (2004b). Avaliação da criatividade por figuras - Teste de Torrance: versão brasileira. Campinas: LAMP-PUC.

Wu, C. H., Cheng, Y., Ip, H. M., \& McBride-Chang, C. (2005). Age differences in creativity: Task structure and 
knowledge base. Creativity Research Journal, 17, 321326.
Yelós, M. L. N. P. (2002). La problemática de la capacitación de docentes en ejercicio: una alternativa de solución. Linhas Críticas, 8, 289-307.

Recebido em: 09/06/2008

Revisado em: 19/06/2008

Aprovado em: 30/06/2008

Sobre os autores:

Júlia Soares Rosa de Castro, Mestre em Psicologia - Secretaria de Estado de Saúde do Distrito Federal

Denise de Souza Fleith (fleith@unb.br) Ph.D. em Psicologia Educacional - Universidade de Brasília

Endereço para correspondência:

Profa. Denise de Souza Fleith

Instituto de Psicologia, Universidade de Brasília

70910-900 Brasília, DF

Email: fleith@unb.br

Telefone: (61) 3326-9441

Fax: (61) 3307-3069

Esta pesquisa, que obteve apoio do CNPq, é parte da dissertação de mestrado da primeira autora orientada pela segunda autora. 